\title{
Modes of failure of proximal femoral nail (PFN) in unstable trochanteric fractures
}

\begin{abstract}
Background: Several fixation devices have been developed to overcome the difficulties encountered in the management of the unstable trochanteric fractures. PFN in unstable fracture patterns is progressively becoming standard method of fixation in view of its superior biomechanics and prevention of varus collapse in comparison to extramedullary devices. However, evolution of PFN is also not free from complications and may comprise complications associated with the migration of the interlocking head screws (Z-effect and reverse Z-effect), varus collapse, screw cutout, peri-implant fracture, non-union, delayed union, shortening and infection.
\end{abstract}

Aims \& Objectives: The objective of the paper is to describe the technical hitches, errors and modes of failure of PFN in unstable trochanteric fractures with their literature-based explanations and the recommendations to avoid such complications.

Materials and methods: The current study is a critical appraisal of the technical hitches, errors and modes of failure of PFN in the course of its evolution in treatment of unstable trochanteric fractures. All patients with unstable trochanteric fractures from July 2013 to June 2015, treated with PFN were included in the study. The technical complications involved with surgical procedure and techniques adapted to overcome such complications were noted. All patients were followed up for a period of 2 years and final outcome assessment comprised the post-operative complications, mobility status, shortening and Harris hip score.

Results: Forty five patients with unstable trochanteric fractures were treated with PFN during the study period. Forty two patients were available for final follow up at 2 years. Technical difficulties with the implantation of the PFN were documented in a total of 16 patients $(35.55 \%)$ which included failed closed reduction in 8 , entry point issues in 7 , guide wire breakage in 3 , fracture at nail tip in 1 , difficulty in proximal locking due to Jig mismatch in 4. Post-operative complications included varus mal-reduction in 4, lag screw cut-out leading to non-union in 2, differential migration of screws in 3 , locking bolt missing the nail hole in 1 and peri-implant fracture in 1. All fractures went into union, except two with mean shortening of $0.5 \mathrm{cms}$. Mean neck shaft angle achieved post reduction was 130.5 degrees (range from 125-137) and at final follow up was 129.8 degrees.

Conclusion: Even though intramedullary fixation is an established method of treatment of unstable trochanteric fractures, the evolution of the procedure is not free from complications. Surgery is technically demanding. However with proper execution, good outcome can be achieved with acceptable rates of complications even in unstable trochanteric fractures. Concerning the techniques making proper entry point, adequate reaming of proximal femur, passing the nail to avoid varus \& distraction at fracture site and placing the lag screw in the inferior part of neck in anterior posterior projection and central in lateral projection reduces risk of fixation failure.

Keywords: Unstable trochanteric fractures, PFN, Z-effect, Reverse Z-effect, Varus collapse, Cut-out

\section{Introduction}

Trochanteric fractures are one of the commonest fractures in aging population. ${ }^{1}$ The prevalence of these fractures has increased substantially over the last few decades as a result of the larger longevity of the population. ${ }^{2}$ About 35 to $40 \%$ of such fractures are unstable one. ${ }^{3,4}$ Surgical stabilization of these fractures is preferred method of treatment for restoring pre-fracture mobility. ${ }^{5,6}$ Several fixation devices have been developed to overcome the difficulties encountered in the management of the unstable trochanteric fractures. Of late, most of these fractures were treated by lateral devices. As lateral devices were associated with high rates of complications ${ }^{7,9}$ intramedullary fixation devices have become gradually more prevalent. ${ }^{10-12}$ The proximal femoral nail (PFN) is an intramedullary system, intended to improve the management of unstable trochanteric fractures. Intramedullary
Volume II Issue I - 2019

\author{
Yasir S Siddiqui,' Abdul Qayyum Khan, ${ }^{2}$ \\ Naiyer Asif, ${ }^{2}$ MJ Khan,' Mohd. Khalid A \\ Sherwani ${ }^{2}$ \\ 'Assistant Professor, Department of Orthopaedic Surgery, J N \\ Medical College, India \\ ${ }^{2}$ Professor, Department of Orthopaedic Surgery, J N Medical \\ College, India
}

Correspondence: Yasir Salam Siddiqui, Assistant professor, Department of Orthopaedic Surgery, J N Medical College,AMU, Aligarh, Uttar Pradesh, India, Tel +919837343400, Email yassu98@gmail.com

Received: January 09, 2019 | Published: January 25, 2019 implants are preferred in treatment of unstable trochanteric fractures, especially in the absence of medial buttress. ${ }^{13,14}$ In 1997 the AO designed an innovative intramedullary implant, the proximal femoral nail (PFN)6 for management of such fractures. Hence, PFN in unstable fracture patterns is progressively becoming standard method of fixation in view of its superior biomechanics and prevention of varus collapse in comparison to extramedullary devices. ${ }^{15}$ However, the evolution of the procedure may include complications associated with the migration of the interlocking head screws (Z-effect and reverse Z-effect), varus collapse, screw cutout, peri-implant fracture, nonunion, delayed union, shortening and infection. The objective of the paper is to describe the technical hitches, errors and modes of failure of PFN in unstable trochanteric fractures with their literature-based explanations and the recommendations to avoid such complications. 


\section{Materials and methods}

The current study is a critical appraisal of the technical hitches, errors and modes of failure of PFN in the course of its evolution in treatment of unstable trochanteric fractures. All patients with unstable trochanteric fractures from July 2013 to June 2015, treated with PFN were included in the study. All the patients gave the informed consent for inclusion into study and the study was approved by the ethical committee of our hospital. The study was performed in harmony with the Ethical standards of the 1964 Declaration of Helsinki as revised in 2000. All unstable fracture patterns according to AO/OTA classification were included in the study ${ }^{16}$ comprising fracture patterns including the reverse oblique, broken lateral wall, trochanteric fracture with subtrochanteric extensions. All patients were evaluated at the end of 2 years. Pre-operative evaluation of the patient included age, sex, mode of injury, fracture classification, pre-operative mobility status, Harris hip score ${ }^{17}$ and other co-morbidities. Patients were operated on fracture table with closed or minimal open reduction to create a mechanically stable fracture-bridging osteosynthesis using PFN. Fixation of fracture with a PFN was carried through longitudinal traction on a fracture table, under $\mathrm{C}$-arm guidance, with five small incisions (one for entry point, two for proximal locking screws and two for distal locking bolts). In the case of failed closed reduction, manipulation with Steinmann pin was done (Figure 1a \& b), and in some cases we have to enlarge the probable incision site for proximal neck screws, so as to apply reduction forceps. For distal locking we mostly used both dynamic and static locking bolts. Both shorter and longer versions of nail were used depending upon the extent of fracture. The intraoperative characteristics studied were duration of surgery, blood loss and technical difficulties encountered in fixation with PFN. Post-operative findings recorded were post-operative complications, mobility status and shortening at final follow-up of 2 years. For better understanding of PFN implantation techniques, the technical hitches were classified into:

1) Issues related to Reduction

2) Issues related to entry point and guide wire placement

3) Issues related to PFN insertion

4) Issues related to accurate placement of lag screw and derotation screw

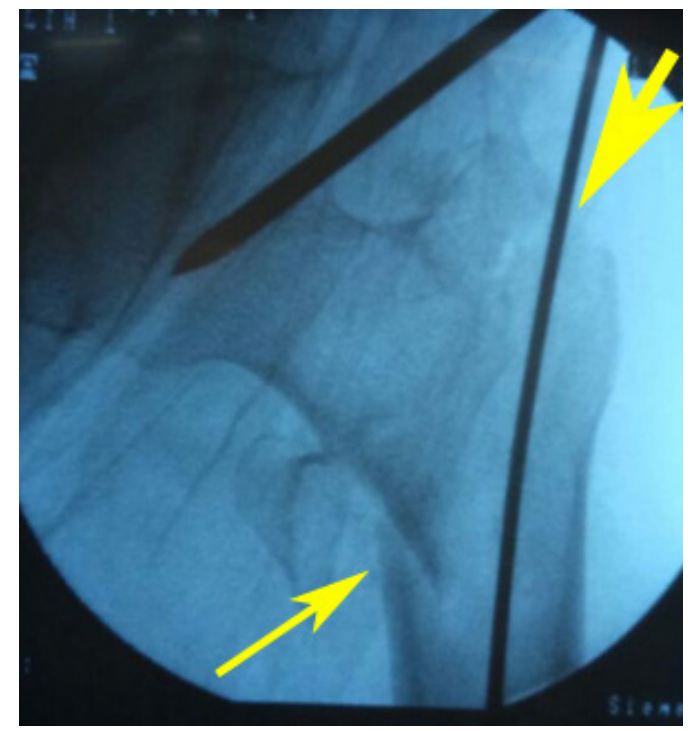

Figure I a Varus reduction as demonstrated by medial overlap of fragments (thin arrow). Also note lateralization of entry point (thick arrow).

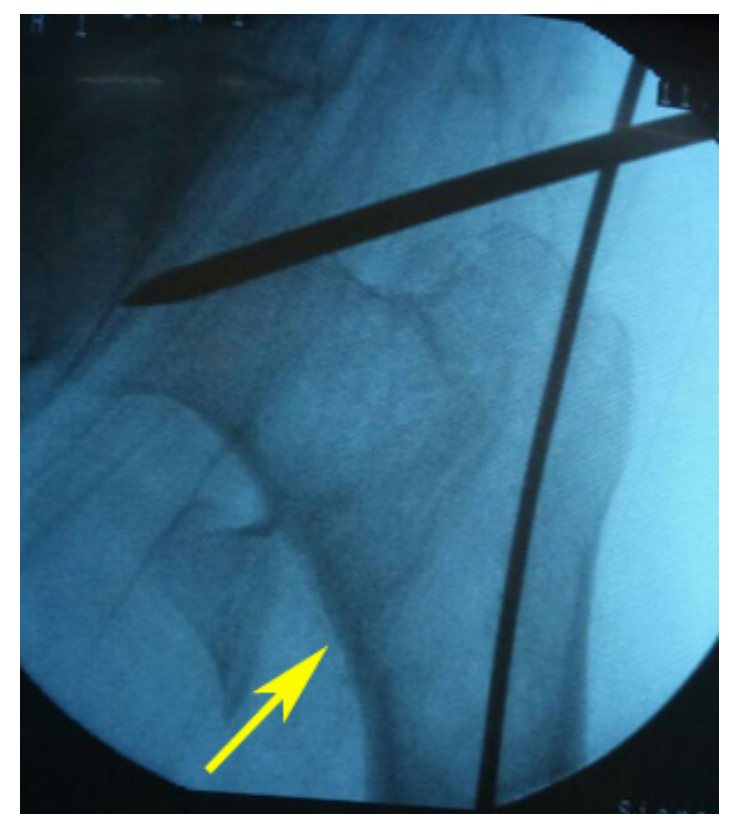

Figure Ib Manipulation with Steinmann pin to correct neck shaft angle as demonstrated by medial continuity and correction of overlap (arrow).

Methods used to solve these problems were noted in the operative notes and these data were used for discussion and analysis.

\section{Results}

A total of 45 patients with unstable trochanteric fractures were treated with PFN from July 2013 to June 2015. Two patients expired within 6 months of surgery and one patient was lost to follow-up; hence were excluded from study. Lastly, 42 patients were available for final analysis (Table 1). Among them there were 23 males and 19 females. Domestic falls were the cause of injury in majority of patients (30 Patients) followed by road side accidents (12 patients). Mean age of patients was 67.4 years (range 27 to 82 years). As per AO/OTA classification, there were 26 type A2 fractures and 16 A3 fractures (thus a total of 42 unstable fractures fixed with PFN were available for critical analysis). Technical difficulties with the implantation of the PFN were documented in a total of 16 patients $(35.55 \%)$ which included failed closed reduction in 8 , entry point issues in 7, guide wire breakage in 3 , fracture at nail tip in 1, difficulty in proximal locking due to Jig mismatch in 4 (Table 2). Closed reduction failed in 8 patients, requiring extension of the probable incision site for proximal neck screws, so as to apply reduction forceps $(17.7 \%)$. Average duration of surgery was 65 minutes (range 45 - 90 minutes). Immediate post-operative AP \& lateral radiograph was assessed for quality of reduction, neck shaft angle (NSA) and position of hip screws. In 38 patients, lag screw was in the centre or inferior position while in 4 it was in the superior part of the head on antero-posterior projection. Post-operative complications included varus mal-reduction in 4, lag screw cut-out leading to non-union in 2 , differential migration of screws ( $Z$ effect/Reverse $Z$ effect) in 3, locking bolt missing the nail hole in 1 and peri-implant fracture in 1. At final follow-up of 2 years, all patients except two with screw cut out and non-union were walking independently. Mean time for fracture union was 6 months. Mean neck shaft angle achieved post reduction was 130.5 degrees (range from 125-137) and at final follow up was 129.8 degrees. Mean limb length discrepancy at final follow up was $0.5 \mathrm{cms}$. Functional assessment with Harris hip score showed almost near return to pre-injury score (pre-injury score of 76 versus final follow-up mean score of 70). 
Table I Demographic and operative details of patients

\begin{tabular}{|c|c|}
\hline $\begin{array}{l}\text { Total no. of patients available for } \\
\text { final follow-up }\end{array}$ & 42 \\
\hline Male : Female Ratio & $23: 19$ \\
\hline Mode of injury & $\begin{array}{l}\text { Domestic falls }=30 \\
\text { Road Side Accident }=12\end{array}$ \\
\hline Mean Age & 67.4 years (Range $27-82$ years) \\
\hline Mean Follow-up & 27 months (Range 24 - 36 months) \\
\hline Blood loss & Approx. $75 \mathrm{ml}$ \\
\hline Mean duration of surgery & 65 minutes (range $45 \mathrm{~min}$. to $90 \mathrm{~min}$.) \\
\hline Mean length of Hospital stay & 7.5 days (Range 5 - I4 days) \\
\hline $\begin{array}{l}\text { Mean time to ambulate with } \\
\text { support }\end{array}$ & Third post-operative day \\
\hline
\end{tabular}

Table 2 Technical difficulties with implantation of PFN

\begin{tabular}{ll}
\hline Technical Hitch & Number \\
\hline Failed closed reduction & 8 \\
Entry point issues & 7 \\
Breakage of guide wires & 3 \\
Fracture of Proximal femur & 0 \\
Fracture at nail tip & $\mathrm{I}$ \\
Difficulty in proximal locking due to Jig mismatch & 4
\end{tabular}

\section{Discussion}

Nevertheless PFN is technically demanding procedure, with appropriate technique; it gives excellent results even in unstable fracture patterns. The important technical aspects are attaining good reduction with acceptable neck shaft angle, making correct entry point, inserting nail properly and precise placement of lag screws.

The technical problems faced during surgery were classified as follows:

1. Issues related to Reduction: Most of the time reduction is achieved on traction table. Acceptable reduction was achieved in all except 8 cases after placing these patients on traction table. While reducing these fractures our aim was to achieve acceptable NSA, length and alignment, rather than solving the jigsaw puzzle by putting each fragment in close approximation anatomically. Closed reduction failed in 8 patients, even after manipulation with Steinmann pin, requiring extension of the probable incision site for proximal neck screws, so as to apply reduction forceps $(17.7 \%)$. K Semmi, et al. ${ }^{18}$ reported that the quality of fracture reduction is an important factor that affects the revision rates and mechanical failures after osteosynthesis with PFN for trochanteric fractures.

2. Issues related to entry point and guide wire placement: Standard entry point for PFN is the tip of greater trochanter. ${ }^{15,19}$ In stable fractures without comminution of greater trochanter, such entry will suffice. However, unstable trochanteric fractures are usually associated with comminution of greater trochanter. Because of comminution, if an entry is made at the tip of trochanter, due to thin bone bridge lateral to tip of trochanter, guide wire and subsequent reamers results in lateralization and enlargement of the entry portal, so much so that after passing of nail through such portal, only the neck screws will be holding the proximal fragment and the nail will be acting as a distracting device, leading to unstable fixation and subsequent fixation failure (Figure 2a). For stable fixation, especially in unstable fracture patterns, there should be some bone bridge available lateral to the nail, so as to provide lateral buttress to the nail and prevent its lateralization (Figure $2 b$ ). Therefore, we recommend the entry should be made just medial to the tip of trochanter and subsequent reaming should be done by keeping reamer as close to the trunk as possible, so as to prevent lateralization and enlargement of the entry portal (Figure 2c). Haidukewych $\mathrm{GJ}^{19}$ also recommends medial entry portal. However P Janardhana Aithala ${ }^{15}$ believes that lateralization of nail will not affect the final outcome as comminuted greater trochanter fragments usually sit around the nail and finally unite. In contrast, we believe for stable fixation, especially in unstable fracture patterns, there should be some bone bridge available lateral to the nail, so as to provide lateral buttress to the nail and prevent lateralization and subsequent fixation failure. We have noticed widening and lateralization of entry portal in 7 patients. Although, we were able to fix all of them with PFN, but in 4 cases with varus mal-reduction and superior placement of lag screws (Figure 2a). Our recommendation for entry point site is just medial to the tip of trochanter and should only be made after reducing the fracture.

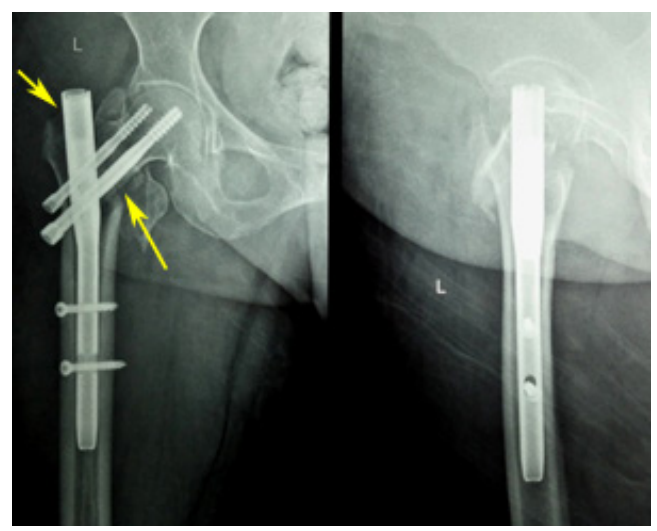

Figure 2a Radiograph showing lateralization and enlargement of the entry portal, with the nail acting as a distracting device (small arrow). Also note the varus mal-reduction (long arrow).

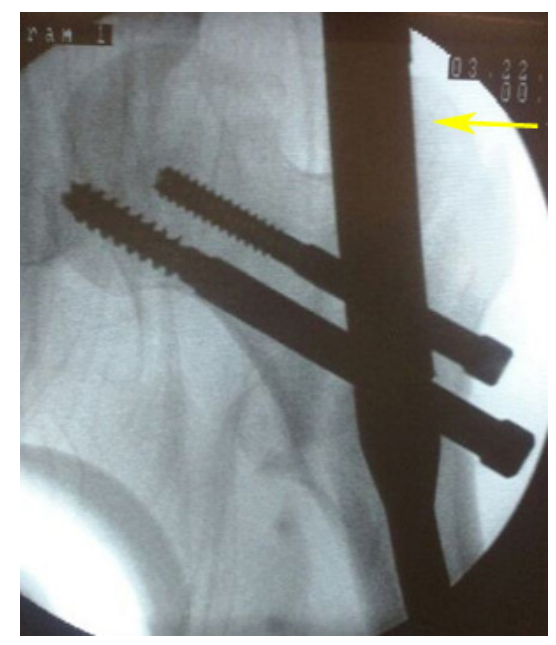

Figure $\mathbf{2 b}$ Bone bridge lateral to the nail, providing lateral buttress to the nail (arrow). 


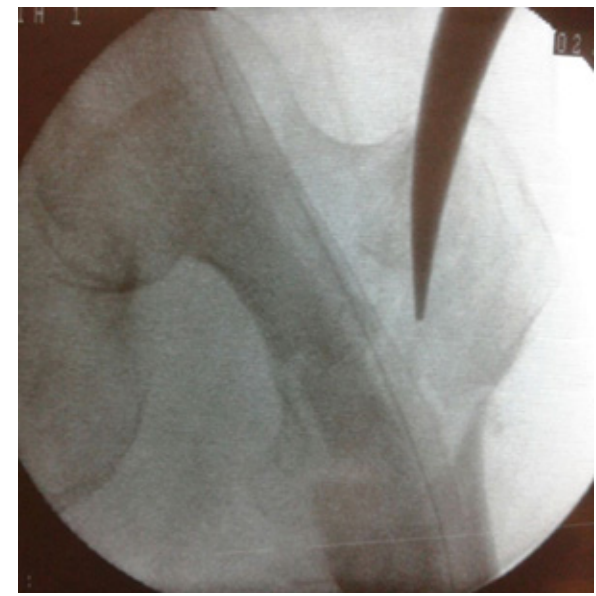

Figure 2c Entry portal just medial to tip of trochanter (arrow).

3. Issues related to PFN insertion: Loss of reduction and possibility of iatrogenic fracture of proximal femur are the two main hitches encountered during insertion of nail. We noticed loss of reduction in 4 cases, while no fracture of the proximal femur was noted during PFN insertion. Loss of reduction with varus of proximal fragment was earlier reported by Hak DJ, et al. ${ }^{20}$ as the wider portion of nail passes through the trochanteric region. This problem was further aggravated when the nail is hammered inside. Varus mal-reduction will result in superior placement of neck screws and subsequent cutout. Nail insertion may also enlarge the entry portal especially in comminuted greater trochanter, thus causing lateralization of the nail, leading to distraction at fracture site. Correction of varus can be done by manipulating proximal fragment with thick K-wire or Steinmann pin, while correction of distraction can be done by applying external pressure over trochanter while passing the nail inside, and continuing the pressure till the lag screw is applied to compress the fracture site. We recommend adequate reaming of the canal so as to provide easy passage for the nail. Preliminary fixation of fracture with K-wire (Figure $3 \mathrm{a} \& \mathrm{~b}$ ) or Steinmann pin can also be done following reduction, before making entry portal, reaming and nail insertion. ${ }^{21}$ Adequate reaming will also prevent iatrogenic fracture of the proximal femur.

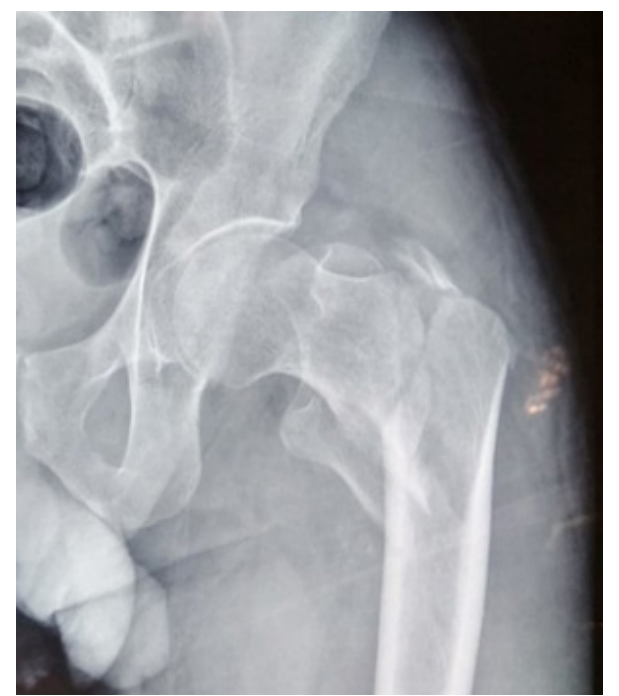

Figure 3a Pre-operative radiograph of patient with 3 IA2 fracture.

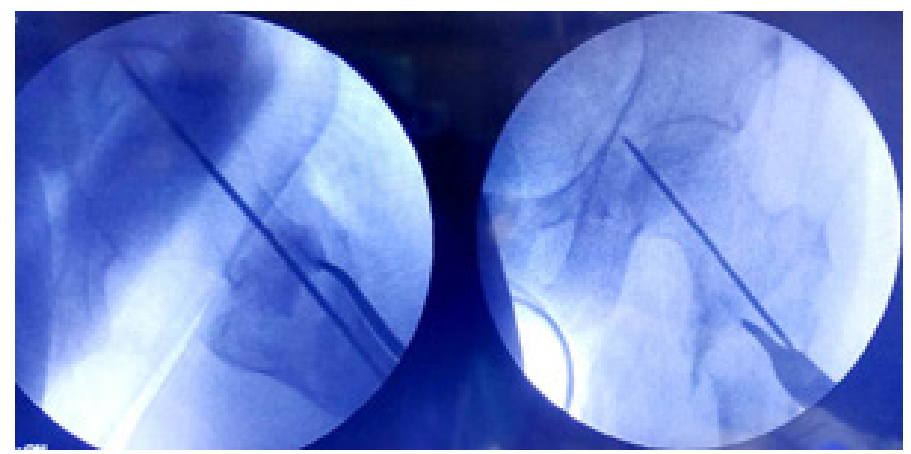

Figure 3b Preliminary fixation with K-wire before making entry point, so as to avoid loss of reduction while reaming and subsequent nail insertion.

4. Issues related to accurate placement of lag screw and derotation screw: Position of the compression screw in both AP \& lateral planes is controversial..$^{19,22,23}$ Some authors favour central-central position, while others recommend inferior (in AP) and central (in lateral plane). We always prefer to pass the lag screw in the inferior part of neck in AP projection and centre in the lateral plane. Inferior placement of lag screw in AP plane prevents backing out of screws due to strong hold in the calcar (Figure 2b). Moreover in dual screw nails, if lag screw is placed in the centre then sometimes superior derotation screw goes too superiorly and even out of superior cortex of neck of femur. In 4 of our cases, position of lag screw was superior and in two of these cases screws had cut out. We regularly pass both guide wires first, followed by passing the lag screw to compress the fracture, and also adding in compression by maintaining external pressure over trochanter. After adequate compression at fracture site we finally place the derotation screw. As far as the length of neck screws was concerned, our aim was to achieve the co-planar alignment of nail tip and the tip of both lag and derotational screw. In our study, derotation screw size was 15 to $20 \mathrm{~mm}$ shorter in comparison to lag screw. Long derotation screws may possibly under the effect of axial loading can back out or migrate into joint leading to Z-effect. ${ }^{24,25}$

There can be hitches while reaming over guide wire for hip screw, as guide wire may bend slightly as it reaches the hard subchondral bone. Drilling over bent guide wire may result in its breakage. We had 3 such complications. We recommend partial drilling over guide wire just proximal to bend, followed by pulling of guide wire up to the level of its bend, then drilling of hard subchondral bone by drill bit itself under $\mathrm{C}$ - arm guidance to prevent guide wire breakage. The guide wire is then reinserted after the removal of reamer for screw insertion. One should also avoid using previously damaged guide wires. Sometimes there is mismatch between the jig and the nail leading to difficulty in negotiating the drill for the hip screws due to some manufacture or implant assembly related problems. We had 4 such problems, three for lag screw and one for derotation screw. Prior to nail insertion, one should check the jig nail assembly for its alignment. Drilling with smaller sized reamer and proceeding with regular reamer will also help. One should also check the jig whether it is loosened or not. Sometimes manipulation and hammering may result in loosening of jig and subsequent mismatch. Sometimes distal locking may also be troublesome. In one of our case distal locking bolt missed the nail while in another hammering the Steinmann pin to make entry portal for locking bolt, resulted in iatrogenic fracture (Figure $4 \mathrm{a} \& \mathrm{~b}$ ). Patient was put on long leg slab, which resulted in 
healing of the iatrogenic fracture. One should always do locking with drill bits and should avoid doing with Steinmann pin and hammer, which may shatter the cortex as was seen in our patient.

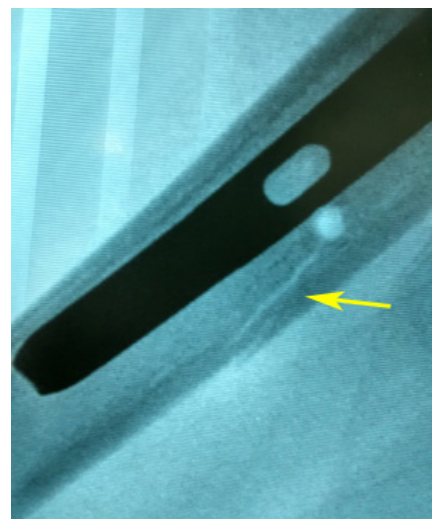

Figure 4a Image showing the iatrogenic fracture of the femur at locking bolt site, as a result of hammering the Steinmann pin to make entry portal for locking bolt (arrow).

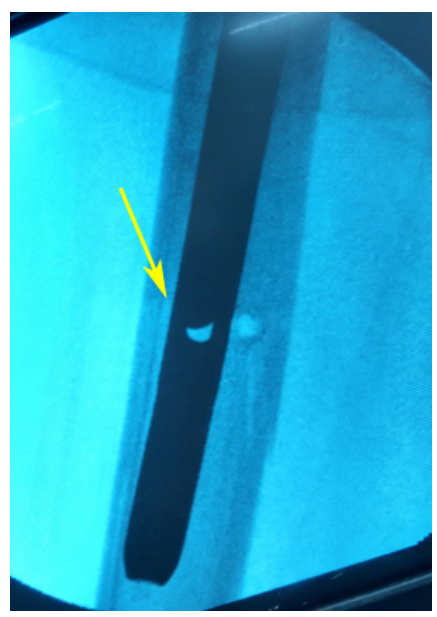

Figure 4b Final image showing the distal locking with iatrogenic fracture of the femur (arrow).

\section{Post-operative complications}

During the observation period there were no postoperative haemorrhages or infections that required therapy. The complications developed following fixation of fractures with the PFN are tabulated in table -3 , and are discussed underneath.

Table 3 Post-operative Complications

\begin{tabular}{ll}
\hline Complications & Number of patients \\
\hline Varus Mal-reduction & 4 \\
Lag screw cut-out & 2 \\
Non-union & 2 \\
Z effect/reverse Z effect & 3 \\
Missed distal locking & I \\
Peri-implant fracture & I \\
Nail breakage & 0 \\
\hline
\end{tabular}

\section{Varus mal-reduction and lag screw cutout}

We have 4 cases of varus mal-reduction. Out of these 4 cases, two patients developed cutout, rest of the two went into successful varus mal-union. The 2 cutouts in our study had a fracture classification of 31-A2.3 and 31-A2.2. In addition, the fractures were inadequately reduced and noted to be fixed into a varus position (Figure $5 \mathrm{a} \& \mathrm{~b}$ ). Placement of hip screw is critical in the ultimate successful outcome of unstable trochanteric fractures. The tip-apex distance (TAD) has been described by Baumgaertner and associates ${ }^{22,23}$ as a useful intraoperative indicator of deep and central placement of the lag screw in the femoral head, regardless of whether a nail or a plate is chosen to fix the fracture. ${ }^{19}$ Position of hip screws in head and neck is dependent on quality of reduction. Varus reduction causes placement of hip screws in superior part of head and neck, leading to varus collapse and early cutout (Figure $5 \mathrm{~b} \& \mathrm{c}$ ). It is important to note that absolute anatomical reduction of unstable trochanteric fractures is a wishful thinking. One should target to achieve antero-medial reduction with correct neck shaft angle. P Janardhana Aithala ${ }^{15}$ also reported that maintenance of correct neck shaft angle and version leads to union, irrespective of comminution and non-anatomical reduction. Hence, the most important technical aspect of PFN implantation is maintaining the appropriate neck shaft angle so as to place hip screws in desirable position. Both are interlinked as screw placement angle is prefixed and hence unless good neck shaft angle is achieved, it is impossible to put the hip screw correctly. In the AP projection, varus at the fracture site is the main hitch to place the screw in centre or inferiorly, while in lateral projection posterior sagging or flexion of proximal fragment is the problem in putting the hip screw centrally. Several studies have reported a cutout rate of $2 \%-8 \% .^{10,26-31}$ We observed a cut-out complication in two patients $(4.76 \%)$. One of them underwent partial hip arthroplasty, whereas the other one opted for implant removal only. Considering the two cut-outs in our study with resultant fixation failure, we believe it is more of technical failure rather than failure of implant. Proper execution of the procedure will give superior results. Our recommendation for lag screw placement position especially in dual screw nails is inferior in AP projection and central in lateral projection.

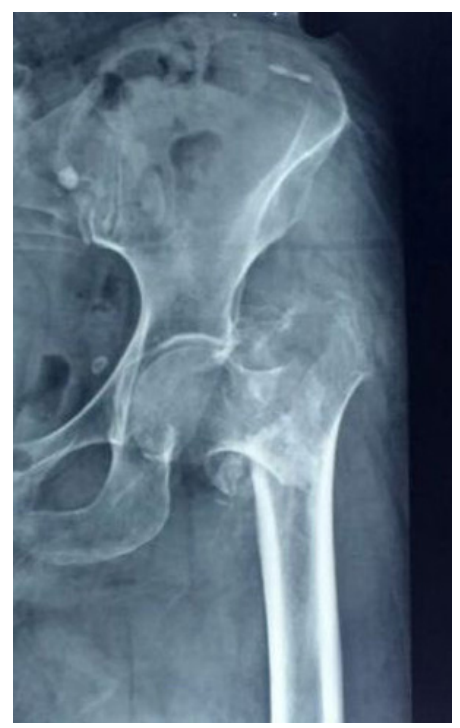

Figure 5a Pre-operative radiograph of patient with 3 IA2.3 fracture with severe osteopenia. 


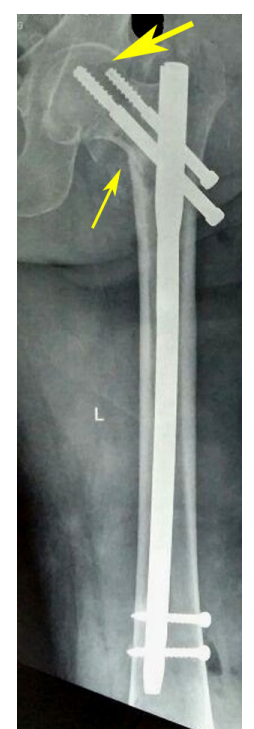

Figure 5b Post-operative radiograph showing varus mal-reduction (pointed by thin arrow as medial overlap of fragments). Also note the superior position of the screws (thick arrow).

\section{Differential migration of screws (Z-effect \& Reverse Z-effect)}

Z-effect and reverse Z-effect are complications that arise from the surgical treatment of trochanteric fractures with PFN comprising two interlocking head screws. Such complications are induced by the migration of screws in opposite directions, which may lead to treatment failure. The Z-effect involves the lateral migration of the lag screw, varus collapse and perforation of the femoral head by the superior derotation screw. The reverse Z-effect involves the lateral migration of the superior derotation screw accompanied by the medial migration of the lag screw. The first account of the Z-effect has been attributed to Werner-Tutshcku, et al. ${ }^{25}$ who reported an incidence of $7.1 \%$ in his study. While the published works designates the Z-effect and reverse Z-effect as the migration of proximal interlocking screws in opposite directions, in practice, sometimes only one screw actually migrates and the fracture undergoes an accommodation process that may lead to the perforation of the femoral head by the screw that remains in the normal position. ${ }^{32}$ Although the cause of this complication has been explained by varus collapse of the fracture and the lack of medial cortical support, its precise etiology requires further elucidation. ${ }^{33}$ Strauss EJ, et al. hypothesized in a biomechanical model that Z-effect \& reverse Z-effect is the result of mismatch between the compressive strengths of the femoral head \& femoral neck (later being lesser), which simulates fractures that have significant medial cortex comminution that are prone to varus collapse. ${ }^{33}$ Weil YA, et al. hypothesized that the nail toggling due to deficient lateral buttress $\&$ an unstable calcar pattern, leads to differential screw migration. ${ }^{34}$ We have total 3 cases of differential migration of screws. They are discussed here in detail (Table 4).

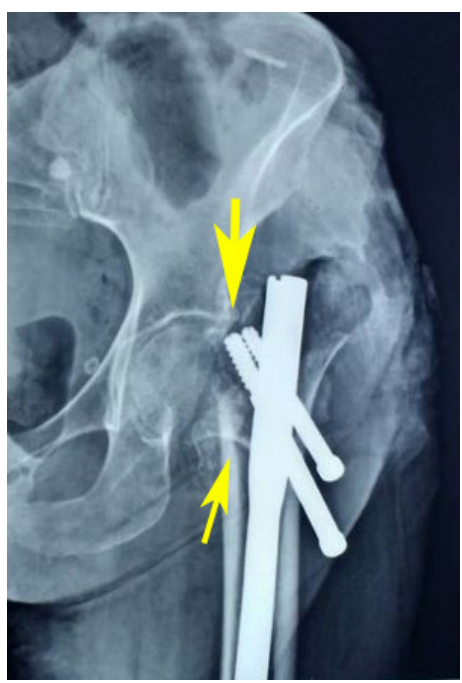

Figure 5c Six weeks post-operative radiograph showing varus collapse (thin arrow), cut-out (thick arrow) and fixation failure.

Table 4 Z-effect/Reverse Z-effect with possible factors contributing for differential migration of hip screws

\begin{tabular}{|c|c|c|c|c|c|}
\hline Case No. & Age/Sex & $\begin{array}{l}\text { Mode of } \\
\text { Injury }\end{array}$ & $\begin{array}{l}\text { Fracture } \\
\text { Classification }\end{array}$ & $\begin{array}{l}\text { Time of development of } \\
\text { Z-effect/Reverse Z-effect }\end{array}$ & $\begin{array}{l}\text { Possible factors contributing for } \\
\text { differential migration }\end{array}$ \\
\hline I & 70 years/Male & $\begin{array}{l}\text { Domestic } \\
\text { Fall }\end{array}$ & $3 \mid \mathrm{A} 2.3$ & Z-effect at 3 months & $\begin{array}{l}\text { I. Unstable fracture pattern } \\
\text { 2. Osteopenia } \\
\text { 3. Superior position and size of screws } \\
\text { 4. Lack of antero-medial buttress } \\
\text { 5. Short nail } \\
\text { 6. Early weight bearing }\end{array}$ \\
\hline 2 & 32 years/Male & $\begin{array}{l}\text { Road side } \\
\text { accident }\end{array}$ & $31 \mathrm{~A} 2.2$ & Reverse Z-effect at 5 months & $\begin{array}{l}\text { I. Unstable fracture pattern } \\
\text { 2. Lack of anterior buttress } \\
\text { 3. Short nail } \\
\text { 4. Early weight bearing }\end{array}$ \\
\hline 3 & 40 years/Male & $\begin{array}{l}\text { Road side } \\
\text { accident }\end{array}$ & $3 \mid \mathrm{A} 3^{.1}$ & Z-effect at 3 months & $\begin{array}{l}\text { I. Unstable fracture pattern } \\
\text { 2. Lack of anterior buttress }\end{array}$ \\
\hline
\end{tabular}

\section{Case I}

A 70 year old male with unstable fracture pattern was submitted to osteosynthesis with PFN. The fracture was classified as AO/OTA type 31A2.3 (Figure 6a). Immediate post-operative radiograph of the patient revealed relatively unstable fracture fixation because of loss of antero-medial buttress, superior placement of hip screws, almost same level of screw tips of both lag and derotation screw (Figure 6b). Because of relatively unstable fracture fixation, patient was advised delayed weight bearing. At home, patient started weight bearing with aid of walking frame. At 3 months post-operative, the patient evolved 
with varus collapse and differential migration of the hip screws, with the caudal one migrating laterally (typical of the Z-effect, Figure 6c). Patient was offered for removal of derotation screw. Patient refused for any surgical intervention as he was up and about with walker with minimal pain.

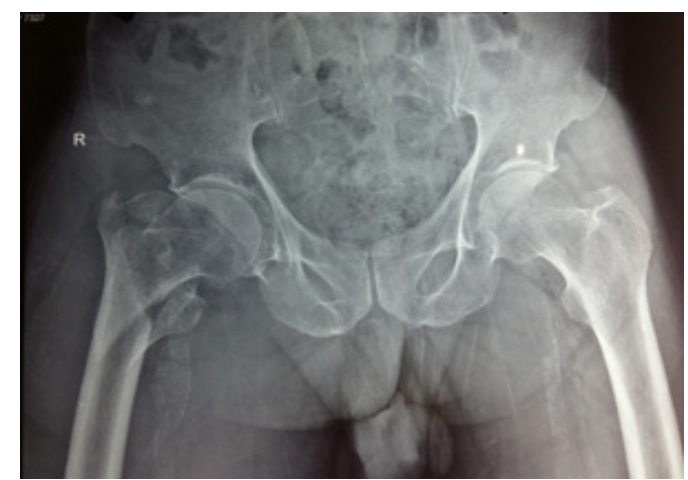

Figure 6a Pre-operative radiograph of patient with $3 \mid \mathrm{A} 2.3$ fracture with osteopenia.

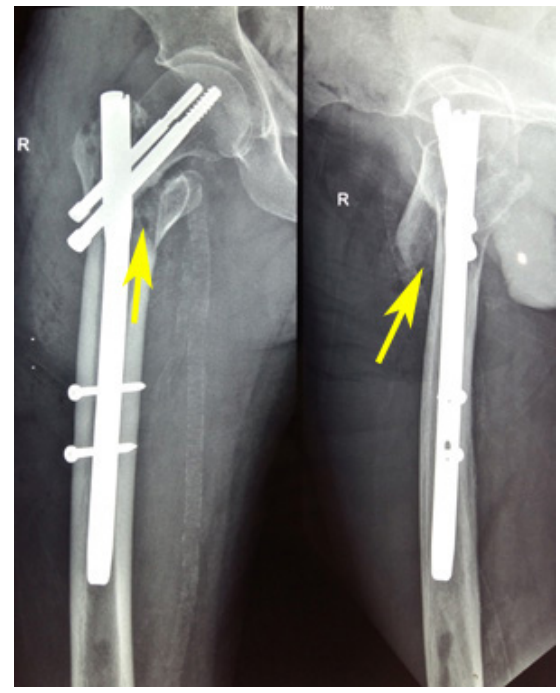

Figure $\mathbf{6 b}$ Immediate post-operative radiograph showing loss of anteromedial buttress (arrows). Also note the superior placement of hip screws \& almost same level of screw tips of both lag and derotation screw.

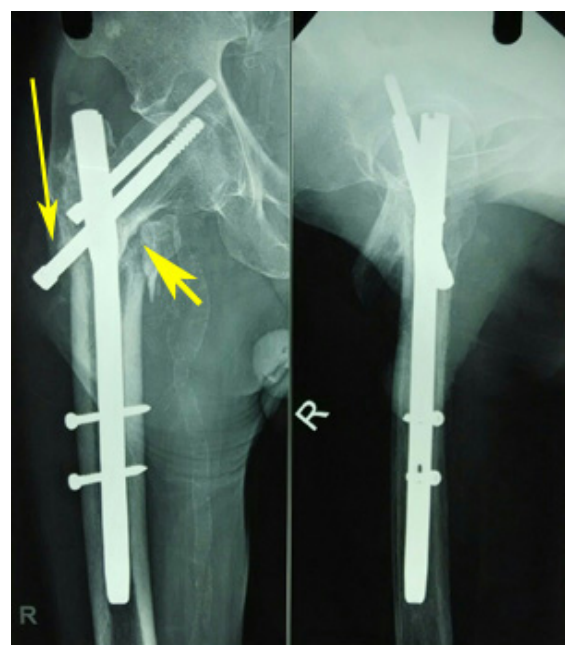

Figure 6c Three months post-operative radiograph showing varus collapse (small arrow) and differential migration of the hip screws (long arrow), with the caudal one migrating laterally (typical of the Z-effect).

\section{Case 2}

A 32-year old male with a road side accident, presented with intertrochanteric fracture of the right femur (AO/OTA 31-A2), The patient was submitted to osteosynthesis with PFN. Immediate post-operative radiograph of the patient revealed acceptable NSA, acceptable position and size of screws, restoration of medial buttress. However anterior bony contact was lacking (lack of anterior buttress). Patient was on regular follow-ups, and at 5 months post-operative he developed varus collapse and reverse Z-effect. Gradually superior derotation screw migrated laterally, with inferior lag screw migrating medially. The resultant varus collapse headed to perforation of the femoral head by the inferior lag screw (reverse Z-effect). As fracture was uniting, we removed the inferior lag screw and tightened superior derotation screw, which lead to successful union of fracture at 9 months. Radiographic images of the patient are presented in Figure 7.

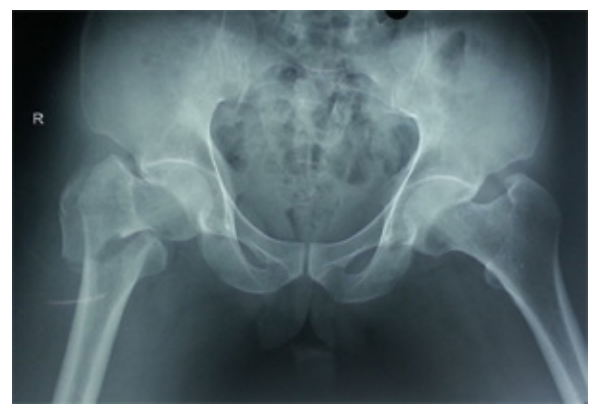

Figure 7a Pre-operative radiograph of patient with $3 \mid \mathrm{A} 2$ fracture.

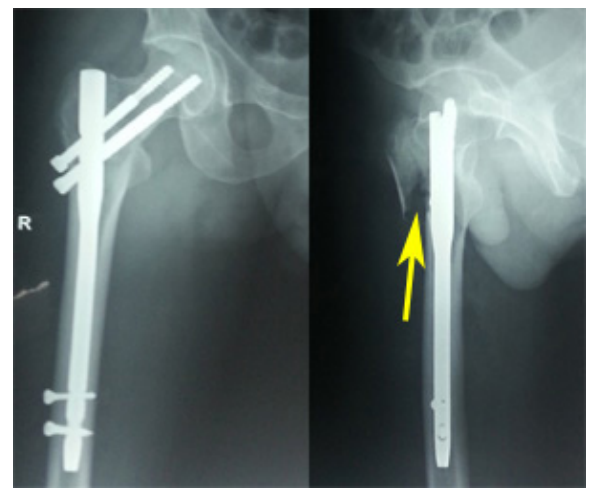

Figure $7 \mathbf{b}$ Immediate post-operative radiograph showing restoration of NSA \& medial buttress. Also note the acceptable position \& size of screws. Arrow in lateral view showing lack of anterior bony contact.

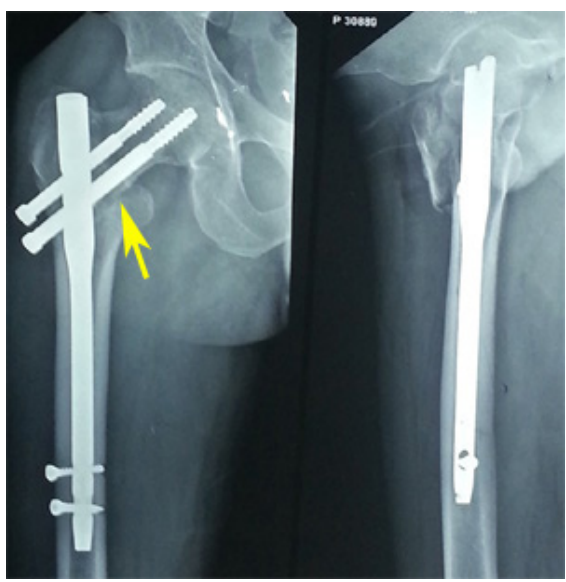

Figure 7c Three months post-operative radiograph showing development of varus at fracture (arrow) and backing out of hip screws. 


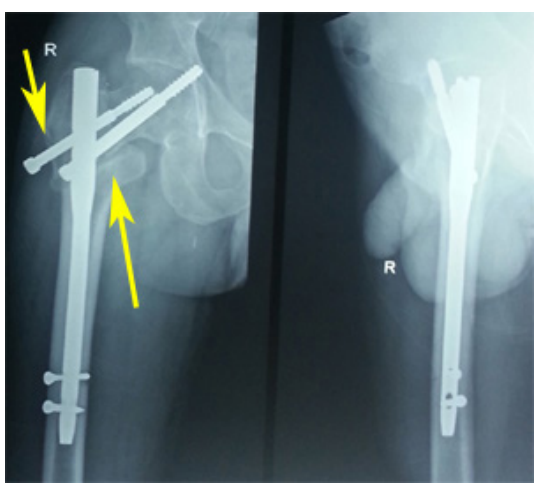

Figure 7d Five months post-operative radiograph showing varus collapse (long arrow) and differential migration of the hip screws (small arrow), with the caudal one migrating medially \& perforating the head (typical of the reverse Z-effect).

\section{Case 3}

A 40-year old male was injured in a road side accident resulting in intertrochanteric fracture of the left femur (AO/OTA 31-A3.1). The patient was submitted to osteosynthesis with PFN. Immediate post-operative radiograph of the patient revealed acceptable NSA, acceptable position and size of screws, restoration of alignment, but not maintaining anterior bony contact. At 3 months post-operative, the patient presented with lateral migration of the lag screw, with the derotation screw maintaining its original position (Z-effect). Patient was kept on strict follow-up, so that any chance of failure of fixation can be detected. At 7 months, patient showed clinico-radiological signs of union. Although, the lag screw moved laterally, but it was still well positioned with regard to the tip apex distance and the fracture was adequately aligned, hence no failure in osteosynthesis occurred. Radiographic images of the patient are presented in Figure 8.

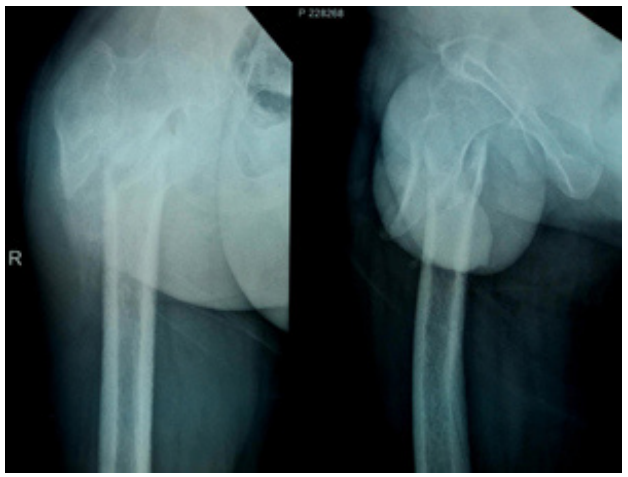

Figure 8a Pre-operative radiograph of patient with 3 IA3.I fracture.

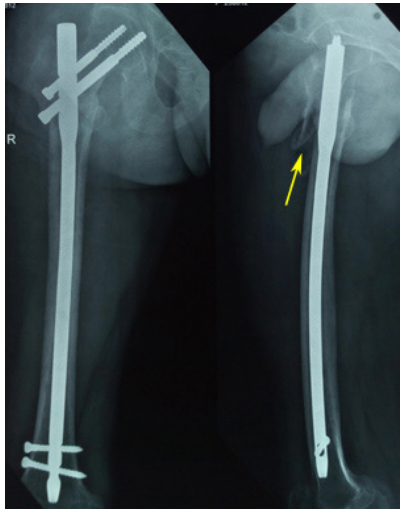

Figure $\mathbf{8 b}$ Immediate post-operative radiograph showing restoration of NSA $\&$ medial buttress. Also note the acceptable position \& size of screws. Arrow in lateral projection showing lack of anterior bony contact.

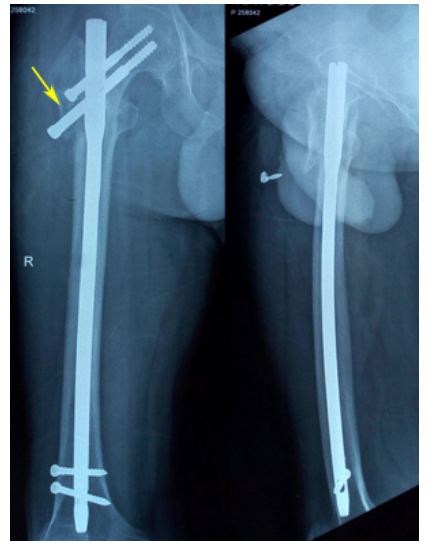

Figure 8c Three months post-operative radiograph showing lateral migration of the lag screw, with the derotation screw maintaining its original position (Z-effect).

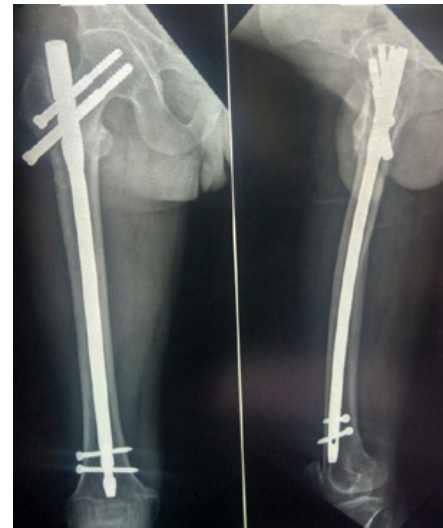

Figure 8d Seven months post-operative radiograph showing fracture union.

\section{Non-union}

Though, postoperative non-union of intertrochanteric fracture is relatively rare, we had 2 cases of cutout leading to non-union. Factors contributing for non-union were fracture fixation in varus, superior placement of screws, osteopenia, and unstable fracture geometry. In our cases, even after fixation of a fracture with PFN, local instability at fracture site persisted leading to abnormal stresses and the fixation failed to provide a stable mechanical environment for fracture healing. One patient underwent arthroplasty procedure while other opted for implant removal only. Radiographic images of one patient are presented in Figure 5.

\section{Peri-implant fracture}

An unavoidable complication of peri-implant fracture occurred in 80 year old lady, following fall at 2 months after fixation of a $31 \mathrm{~A} 2$ fracture with a PFN. She sustained a femoral shaft fracture at the level of the distal locking bolt (Figure 9). By changing the implant for a longer nail, we were able to achieve healing of the fracture. Initially patient was fixed with shorter version of PFN. Our recommendations for fixation of unstable trochanteric fractures with osteoporosis are to put longer nails, so as to splint the whole femur.

Our study highlights the technical hitches and modes of failure of PFN in unstable fracture pattern, but small sample size and retrograde design of study are the limitations of current study. Further studies are required to focus on improving the techniques of PFN and augmenting its stability, especially in unstable osteoporotic fractures to make the evidence strong that good outcome can be achieved with acceptable rates of complications in unstable trochanteric fractures. 


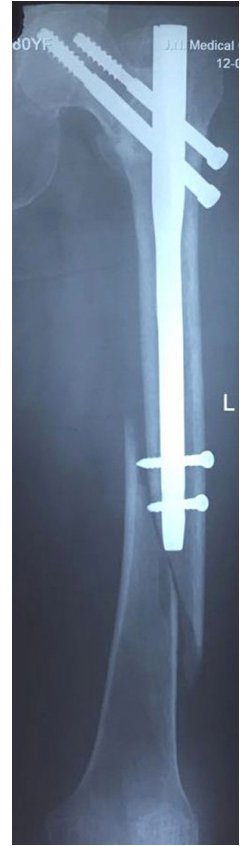

Figure 9 Radiograph of patient with peri-implant fracture as a result of fall.

\section{Conclusion}

Even though intramedullary fixation is an established method of treatment of unstable trochanteric fractures, the evolution of the procedure is not free from complications. Considering the failures in our study, we believe they are more of a technical failure, rather than failure of implant. Achieving good reduction (maintaining NSA, alignment \& length) and placement of hip screws in a correct position are two important technical characteristics which prevent most of the complications associated with PFN. Although surgery is technically demanding, if one gives vigilant attention to minute technical aspects of the procedure as discussed above, good outcome can be achieved with acceptable rates of complications even in unstable trochanteric fractures.

\section{Acknowledgment}

None.

\section{Conflicts of interest}

None.

\section{References}

1. R Marks. Hip Fracture Epidemiological Trends, Outcomes, and Risk Factors, 1970-2009. Int J Gen Med. 2010;3:1-17.

2. Brunner A, Jöckel JA, Babst R. The PFNA proximal femur nail in treatment of unstable proximal femur fractures--3 cases of postoperative perforation of the helical blade into the hip joint. $J$ Orthop Trauma. 208;22(10):731-736

3. Sidhu AS, Singh AP, Singh AP, et al. Total hip replacement as primary treatment of unstable intertrochanteric fractures in elderly patients. Int Orthop. 2008;34(6):789-792.

4. HG Ebrahim, KO Farzad, H Hossein, et al. How to Treat the Complex Unstable Intertrochanteric Fractures in Elderly Patients? DHS or Arthroplasty. Arch Bone Jt Surg. 2014;2(3):174-179.

5. Sturmer KM, Dresing K. Pertrochanteric fractures. Zentralbl Chir 1995;120(11):862.
6. Joachim W, H Dirk A, H Mohssen, et al. Pitfalls and complications in the use of the proximal femoral nail. Langenbecks Arch Surg. 2005;390:5965.

7. Davis TR, Sher JL, Horsman A, et al. Intertrochanteric femoral fractures: mechanical failure after internal fixation. J Bone Joint Surg Br. 1990;72(1):26-31.

8. Kyle RF, Gustilo RNB, Premer RF. Analysis of six hundred and twenty-two intertrochanteric hip fractures. J Bone Joint Surg Am. 1979;61(2):216-221.

9. Simpson AH, Varty K, Dodd CA. Sliding hip screws: modes of failure. Injury. 1989;20(4):227-231.

10. Schipper IB, Steyerberg EW, Castelein RM, et al. Treatment of unstable trochanteric fractures- randomised comparison of the gamma nail and the proximal femoral nail. J Bone Joint Surg Br. 2004;86(1):86-94.

11. Schwab E, Höntzsch K, Weise K. Die Versorgung instabiler perund subtrochantärer Femurfrakturen mit dem Proximalen Femurnagel (PFN). Akt Traumatol. 1998;28:56-60.

12. David A, von der Heyde D, Pommer A. Therapeutic possibilities in trochanteric fractures: safe-fast-stable. Orthopade. 2000;29:294-301.

13. Ahrengart L, Tornkvist $\mathrm{H}$, Fornander $\mathrm{P}$, et al. A randomized study of the compression hip screw and Gamma nail in 426 fractures. Clin Orthop. 2002;401:209-222.

14. Pervez H, Parker MJ. Results of the long Gamma nail for complex proximal femoral fractures. Injury. 2001;2:704.

15. P Janardhana Aithala, R Sharath. Proximal Femoral Nailing: Technical Difficulties and Results in Trochanteric Fractures. Open Journal of Orthopedics. 2013;3:234-242.

16. Grimsrud C, Monzon RJ, Richman J, et al. Cemented hip arthroplasty with a novel cerclage cable technique for unstable intertrochanteric hip fractures. J Arthroplasty. 2015;20(3):337-343.

17. WH Harris. Traumatic Arthritis of the Hip after Dislocation and Acetabular Fractures: Treatment by Mold Arthroplasty. An End Result Study Using a New Method of Result Evaluation. J Bone Joint Surg Am. 1969;51(4): 737-755.

18. K Şemmi, A Taşkın, K Cemil, et al. Mechanical failures after fixation with proximal femoral nail and risk factors. Clin Interv Aging. 2015;10:19591965.

19. Haidukewych GJ. Intertrochanteric fractures: ten tips to improve results J Bone Joint Surg Am. 2009;91(3): 712-719.

20. DJ Hak, C Bilat. Avoiding varus Malreduction during Cephalomedullary Nailing of Intertrochanteric Hip Fractures. Arch Orthop Trauma Surg. 2011;131(5):709-710.

21. Jain MJ, Mavani KJ, Patel D. Role of Provisional Fixation of Fracture Fragments By Steinmann-Pin and Technical Tips in Proximal Femoral Nailing for Intertrochanteric fracture. J Clin Diagn Res. 2017;11(6):1-5.

22. Baumgaertner MR, Curtin SL, Lindskog DM, et al. The value of the tipapex distance in predicting failure of fixation of peritrochanteric fractures of the hip. J Bone Joint Surg Am. 1995;77(7):1058-1064.

23. Baumgaertner MR, Solberg BD. Awareness of tip-apex distance reduces failure of fixation of trochanteric fractures of the hip. J Bone Joint Surg Br. 1997;79(6):969-971.

24. Morihara T, Arai Y, Tokugawa S, et al. Proximal femoral nail for treatment of trochanteric femoral fractures. J Orthop Surg (Hong Kong). 2007;15(3):273-277.

25. Werner-Tutschku W, Lajtai G, Schmiedhuber G, et al. Intraund perioperative Komplikationen bei der Stabilisierung von perund subtrochantären Femurfrakturen mittels PFN. Unfallchirurg. 2002; 105:881-885 
26. Akan K, Cift H, Ozkan K, et al. Effect of osteoporosis on clinical outcomes in intertrochanteric hip fractures treated with a proximal femoral nail. J Int Med Res. 2011;39(3):857-865.

27. Ma KL, Wang X, Luan FJ, et al. Proximal femoral nails antirotation, Gamma nails, and dynamic hip screws for fixation of intertrochanteric fractures of femur: a meta-analysis. Orthop Traumatol Surg Res. 2014;100(8):859-866.

28. Shen L, Zhang Y, Shen Y, et al. Antirotation proximal femoral nail versus dynamic hip screw for intertrochanteric fractures: a metaanalysis of randomized controlled studies. Orthop Traumatol Surg Res. 2013;99(4):377-383.

29. Uzun M, Ertürer E, Oztürk I, et al. Long-term radiographic complications following treatment of unstable intertrochanteric femoral fractures with the proximal femoral nail and effects on functional results. Acta Orthop Traumatol Turc. 2009;43(6):457-463.

30. Erturer RE, Sönmez MM, Sari S, et al. Intramedullary osteosynthesis of instable intertrochanteric femur fractures with Profin ${ }^{\circledR}$ nail in elderly patients. Acta Orthop Traumatol Turc. 2012;46(2):107-112.
31. Boldin C, Seibert FJ, Fankhauser F, et al. The proximal femoral nail (PFN)-a minimal invasive treatment of unstable proximal femoral fractures: a prospective study of 55 patients with a follow-up of 15 months. Acta Orthop Scand. 2003;74(1):53-58.

32. Pires RE, Santana EO Jr, Santos LE, et al. Failure of fixation of trochanteric femur fractures: Clinical recommendations for avoiding Z-effect and reverse Z-effect type complications. Patient Saf Surg. 2011;5:17.

33. Strauss EJ, Kummer FJ, Koval KJ, et al. The "Z-effect" phenomenon defined: a laboratory study. J Orthop Res. 2007;25(12):1568-1573.

34. Weil Y, Gardner M, Mikhail G, et al. Medial migration of intramedullary hip fixation devices: a biomechanical analysis. Arch Orthop Trauma Surg. 2008;128:227-234. 